Accepted

15. 1. 2020

Revised

17. 2. 2020

Published

24. 4. 2020

Keywords

international surrogacy arrangements, international regulation, reform of international adoption procedure, recognition of legal parentage,

the best interest of the child.

\section{INTERNATIONAL SURROGACY \\ ARRANGEMENTS - PERSPECTIVES ON \\ INTERNATIONAL REGULATION}

\author{
JASMINA AlihODŽIĆ ${ }^{1} \&$ ANITA DURAKOVIĆ ${ }^{2}$ \\ ${ }^{1}$ University of Tuzla, Faculty of Law, Tuzla, Bosnia \& Herzegovina, \\ e-mail: jasmina.altumbabic@untz.ba \\ ${ }^{2}$ University "Džemal Bijedić", Faculty of Law, Mostar, Bosnia \& Herzegovina, \\ e-mail: anita.durakovic@unmo.ba \\ CORRESPONDING AUTHOR \\ jasmina.altumbabic@untz.ba
}

\begin{abstract}
Although more than 30 years have passed since the birth of the first surrogate baby, surrogacy motherhood as a form of ART is still one of the most controversial issues that reflect moral, ethical, cultural, psychological, medical, economic and legal dilemmas. The juxtaposition of legal solutions at the national level has given rise to discussions on the optimal solutions for regulating model international surrogacy arrangements. Given the current social and political climate, the authors of this paper advocate for the reform of international adoption procedures as opposed to passing a new convention, in a way that respective provisions of international adoption convention should be adapted to capture the effects of international surrogacy arrangements - recognition of legal parentage, provided that it is in the best interests of the child, and that there is a biological link between the child and at least one intended parent.
\end{abstract}




\section{$1 \quad$ Introduction}

Recent developments and research in the field of reproductive medicine have provided infertile couples with new opportunities to have a child. One form of biomedically assisted fertilization is the surrogacy in a situation where a woman, for various reasons, is unable or unwilling to give birth. However, surrogacy motherhood, with or without an international element, is a topic on which, due to the numerous dilemmas of an ethical, legal, religious and social nature, no international consensus can be reached. Different perceptions globally have led to major inconsistencies with regard to the regulation of surrogacy in national legislations. The practices of certain countries shows that the intention of the legislators to expressly prohibit surrogacy by operation of law will certainly not, and probably has not, prevented interested couples from seeking to implement these arrangements abroad. In this context, one is faced with the notion of an international surrogacy arrangement or surrogate motherhood with cross-border effects. Considering the divergent solutions of national substantive provisions regarding surrogacy, and the legal consequences arising from relations with a cross-border element, it is necessary to analyze the mechanisms of private international law in the context of recognition of the legal parentage of a child born through an international surrogacy arrangement. In this paper, in addition to presenting both the theoretical and legal views related to the international regulation of surrogacy, the authors also will analyze the work done so far within the Hague Conference on Private International Law. They also will propose a solution that they consider optimal for the regulation of issues arising from the realization of international surrogacy arrangements, while keeping in mind the best interests of the child.

\section{Theoretical and legal opinions: pros and cons of the specific international instrument}

Currently, from a worldwide perspective, there is no uniformity in the manner in which various countries have regulated surrogacy arrangements. This lack of uniformity, when coupled with both the absence of a normative framework at the international level, and that the practice involves a significant number of international surrogacy arrangements, has lead to legal and practical uncertainties and raises many questions. Some of these issues relate to the link between the realization of an international surrogacy arrangement and fundamental rights 
guaranteed by national and international legal acts, such as the right to privacy and family life, the right to freedom of movement, the rights of the child, etc. In addition, there are irreconcilable views between countries that allow surrogate motherhood and those who prohibit it. Furthermore, even if the national legislator opts to ban surrogacy motherhood altogether, in reality such a decision will not eliminate the cross-border implementation of these arrangements. In relation to the above, it is necessary to answer the question: is there a need for regulatory or normative action at the international level? If the answer to the previous question is affirmative, then a number of important issues must be confronted and resolved. For example, should surrogate motherhood be regulated by an entirely new, unique instrument that would comprehensively address the principal issues surrounding surrogacy, including the issue of legal parenthood, the nationality of the child, the coordinated action of the various agencies which are involved in mediating the implementation of surrogate arrangements, etc., or instead should such legislative intervention be more restrained and aimed at modulating existing international instruments that regulate some issues of a private law nature in this domain, e.g. Convention on Intercountry Adoption? Furthermore, given the nature of such an instrument, questions arise concerning its effects. For example, should such a regulatory form be binding on Member States or should its function be exhausted through the operation of a non-binding model of law, guidance or principle?

It is indisputable that any form of international legislative intervention in the field of regulating international surrogacy arrangements must strike an appropriate balance between the interests of the various participants in such arrangements. Those interests, guaranteed by the European Convention for the Protection of Human Rights and Fundamental Freedoms (right to privacy and family life), are manifested as the right of intended parents to exercise legal parenthood over a child. However, these rights are often in direct conflict with the democratic choices made by national legislators that prohibit the recognition of such arrangements, by invoking the protection of their own public order, namely the protection of the rights of the child, that is, to achieve the standard of his or her best interest. From a comparative law prospective, it should not be forgotten that today, with regard to this issue, the most controversial legal solutions are present, which find their foundations in various cultural, historical, medical, sociological, psychological and other factors. 
When it comes to the need and method of regulating cross-border surrogacy at the international level, the opinions are divided in legal theory. According to one, regulating international surrogacy with a completely new international instrument is unlikely to succeed, precisely because of the fact that it is difficult to reach consensus internationally given the diverse issues surrounding the realization of surrogacy and the differing attitudes of states in this regard. According to L. Pluym, for the international regulation of surrogate motherhood to be effective, it is necessary to strike a balance of interests between legal systems that allow surrogate arrangements (including commercial) and where intended parents typically travel to for its realization, such as for example, California, Ukraine, India and legal systems that prohibit surrogate motherhood, and from where the intended parents are usually gtraveling from in order to pursue surrogacy arrangements, e.g. France, Germany, Belgium, etc. (Pluym, 2014: 337-338). The same author believes that global approaches to surrogacy arrangements are so diverse, that it seems simply impossible for an international instrument to achieve anything more than superficial normative regulation (Pluym, 2014: 337-338). The biggest "stumbling block" is, in her opinion, the issue of commercial surrogacy arrangements, which should be covered by a future international instrument, because in most situations involving the realization of international surrogacy arrangements, the surrogate mother is paid for the birth service for another, and these amounts often exceed the real costs of pregnancy and childbirth (Pluym, 2014: 337-338).

Instead of instituting a new international instrument to regulate surrogacy, C. Thomale believes that the focus of legal reform should be to adapt the existing legal framework on intercountry adoption to cases of international surrogacy arrangements (Thomale, 2017: 471-473). Specifically, this author doubts that the adoption of a new mechanism in the form of an international convention focusing on the recognition of a foreign court decision on legal parentage, or a public document confirming the legal parentage of intended parents, established in the country of origin of the decision, would be in the best interest of the child (Thomale, 2017: 469-470). This author goes one step further by expressing doubt as to whether the recognition of a foreign judgment on legal parentage would be in the best interests of either the intended parents or the child (Thomale, 2017: 469-470). 
This contention seems entirely rational given that most legal systems that explicitly prohibit surrogate motherhood, when it comes to the recognition of foreign judicial and other decisions, accept a system of limited control over them, such as Germany, Austria, Slovenia, Bosnia and Herzegovina (Muminović, 2006: 83-84). This implies that the authorities of the State of recognition will not weigh into the merits of the decision, but rather when examining the eligibility of the decision for recognition, are guided solely by conditions determined by the law. With respect to a foreign court decision establishing the legal parentage of the intended parents of the child, this means that the authority in the country of recognition does not have the opportunity to examine de novo the facts and conditions under which the surrogate motherhood was established abroad and whether its realization is indeed in the best interest of the child or that some other interests are satisfied by this procedure. If, in the light of the above, the best interests of the child are considered as the primary criterion, it can be concluded that it is not justifiable to give greater weight to the recognition of a foreign court decision on legal parentage over a child resulting from the realization of a surrogate arrangement, and which is in the focus of regulation at international level, than to some other parent-child relationships, such as adoption, foster care, etc. According to Thomale, up to the moment of recognition of the foreign court decision establishing the legal parentage of the intended parents, and on the basis of the facts available to the court, the only characteristics that the intended parents could show to the court were their willingness to pay and to avoid national law. That is to say, characteristics that any child buyer may have. Consequently, it is fallacious to conclude, relying solely on those limited characteristics, that recognition would be better for the child than foster care, adoption or public care (Thomale, 2017: 470). From the foregoing, it can be concluded that it would be very difficult to justify the fact that States which explicitly prohibit surrogacy in their national legislation should recognize judicial decisions or public documents on surrogate motherhood established abroad, especially if the case is closely related to the country of recognition (for example, if the intended parents are nationals of the country of recognition and intend to live there, the child is domiciled in the country of recognition). Therefore, some legal theorists emphasize that adoption should be given priority, as a procedure that genuinely protects and favors the best interests of the child over recognition of legal parentage established abroad, whether it is recognition of a foreign court decision establishing legal parentage or recognition of a public document proving the status of legal parents (Thomale, 2017: 471). 
The procedure for intercountry adoption is regulated at the international level by the Convention on Protection of Children and Cooperation in Respect of Intercountry Adoption (hereinafter: the Convention on Intercountry Adoption) from 29 May 1993, which entered into force on 1 May $1995 .{ }^{1}$ The aim of the Convention on International Adoption is to establish guarantees for the establishment of intercountry adoption that are in the best interests of the child and respect for the fundamental rights recognized by international law. ${ }^{2}$ Article 26 of the Convention on Intercountry Adoption provides that recognition of adoption shall include recognition of the parental relationship between the child and its adoptive parents, as well as the rights of adoptive parents to the child. As this international instrument does not cover the cases of parental relationship established by the realization of surrogacy arrangements, its adaptation should be carried out for the eventual application of this Convention to the recognition of legal parentage resulting from international surrogacy cases. Thomale states that adapting the procedure for adoption to international surrogacy arrangements should be the focal point of legal reform (Thomale, 2017: 471). This adaptation, in the author's view, would primarily relate to the possibility of an expedited and simplified adoption procedure. This would be the case both in situations where the child is born through a surrogacy arrangement and whose genetic link to the intended parents can be established as well as where the legal parentage of one of the intended parents is already specifically established, so that the adoption procedure is focused only on the other intended parent (Thomale, 2017: 471). Alternatively, the request of intended parents for adoption of a child born through international surrogacy may be seen as a priority on the request list or given special treatment in the adoption process (Thomale, 2017: 471). Expanding the scope of the Convention on Intercountry Adoption, or modifying it with respect to the recognition of legal parentage arising from international surrogacy, could represent a valid and legitimate alternative to the adoption of a separate international instrument governing the recognition of foreign court decisions or public legal documents on legal parentage arising from international surrogacy arrangements. The modified or adapted adoption procedure has the capacity to safeguard the best interests of the child, in the sense that a detailed examination of the conditions of adoption, which would be carried out in accordance with the provisions of this Convention on Intercountry Adoption, aims

\footnotetext{
${ }^{1}$ Convention of 29 May 1993 on Protection of Children and Co-operation in Respect of Intercountry Adoption, https://www.hcch.net/en/instruments/conventions/status-table/?cid=69, page access 22.09.2019.

${ }^{2}$ Article 1 paragraph 1 in relation with article 15, 16, and 26 of the Convention on International Adoption.
} 
to determine, inter alia, whether it is in the best interests of the child that the intended parents be his or her legal parents. ${ }^{3}$

On the other hand, other legal commentators argue that a superior solution rests with instituting an entirely new international instrument (Trimmings \& Beaumont, 2013: 633-647; Meilhac-Perri, 2014: 284-286; Margalit, 2016: 68-81; Rokas, 2014: 300-306). As a result of their research, Trimmings and Beaumont offered a proposal for such an instrument, which would be based on the existing 1993 Intercountry Adoption Convention (Trimmings \& Beaumont, 2013: 633-647). The functioning of the system, as proposed by this research, would be based on two fundamental principles: one that advocates both the preservation of the best interests of the child and the biological connection between the child and at least one intended parent (Trimmings \& Beaumont, 2013: 640-641). Legislatively, this proposed mechanism does not aim to achieve the unification of conflict-of-law rules, but instead should focus on building a system of legally binding minimum standards applicable to the surrogacy arrangement procedure; establishing mechanisms to ensure the protection of these minimum standards; and, establishing a framework for cooperation and channels of communication between different national jurisdictions that are associated with the realization of surrogacy arrangements (Trimmings \& Beaumont, 2011: 636).

The proposal for a new convention accepts a compromise solution in relation to the model of surrogacy. For example, under the new convention it would be acceptable to pay justified and necessary costs to the surrogate mother for such items as lost wages, reasonable living expenses, medical and other costs associated with pregnancy, etc. (Trimmings \& Beaumont, 2011: 643-645). In order to avoid abuse and financial gain from the realization of surrogacy arrangements, the authors note that it would be necessary to ensure the transparency of the requests for, and reimbursement of, such costs and fees. However, due to differences in revenues and costs across countries, the financial calculation of these costs would be subject to regulation by national authorities (Trimmings \& Beaumont, 2011: 644). The proposal for such a convention is conceptualized on the system of prior approval of each international surrogacy arrangement.

${ }^{3}$ Article 4. and 5. Convention on Intercounty Adoption. 
In the authors' view, the legal status of intended parents with children born through a pre-approved surrogacy arrangement will be guaranteed by automatic recognition in the intended parent's country of origin (Trimmings \& Beaumont, 2011: 645). However, a counter argument to such a proposal might be reflected in a question of why would countries that prohibit surrogacy motherhood in their national law give prior approval to the realization of a surrogacy arrangement abroad, and ultimately acknowledge it (Rokas, 2014: 303)? The authors of the proposal further assume that the adoption of an international instrument to regulate surrogacy not only would facilitate the exchange of information but also reduce both the number of "limping" family relationships and the number of cases of trafficking in women and children (Rokas, 2014: 301-302). The framework of cooperation envisaged by the draft convention is based on the division of responsibilities between the country of origin of the intended parents and the country of birth of the child. Thus, the law of the intended parents' habitual residence would be relevant for assessing not only the eligibility conditions for the intended parents (age, existence of a valid marriage, stable family environment, family and medical history, etc.), but also other factors affecting the realization of a surrogacy arrangement (e.g. consent and assistance with the entry of the child into the country of its permanent residence/country of origin of the intended parents). On the other hand, the law of the surrogate mother's country or the country of the birth of the child would be relevant for fulfilling the conditions on the surrogate mother's side (age, marital status, request on a pre-birth of a live child, adequate preparation, awareness of the surrogate mother, anticipation of adequate financial compensation for the surrogate mother, approval of the child's departure from the country of birth under an adoption order or other order, etc.) (Trimmings \& Beaumont, 2011: 641-643). In the opinion of many other authors, the results of the research provided in the form of the convention proposal are noteworthy because they offer pragmatic solutions to the crucial issues that arise in connection with the realization of international surrogacy arrangements (Rokas, 2014: 302). Some of these proposed solutions relate to the legal status of the child, as well as to all other persons involved in the process of implementing a surrogacy arrangement. The advantage of such a proposed system is certainly reflected in the fact that it is based on the already existing successful model of the Convention on Intercountry Adoption. Perhaps, however, the most significant contribution of this research is that it summarizes in a concise and thorough way all the complexities of the surrogacy phenomenon, both in terms of legislation and in terms of the practical realization of these arrangements. Although in principle they support the regulation 
of surrogacy by a new international instrument, numerous legal theorists point out a number of burdensome issues that may ultimately preclude the conclusion of such a multilateral convention (Blauwhoff \& Frohn, 2016: 211-241). Blauwhoff and Frohn are also in favour of regulating surrogacy through a special international instrument. However, due to the complex nature of surrogacy arrangements with an international element, and the huge variations in the laws of different countries regarding the regulation of surrogacy, these authors believe that for the time being, it is unlikely that these issues will be addressed internationally by a single comprehensive instrument of private international law. (Blauwhoff \& Frohn, 2016: 238). In their view, focus instead should be geared towards adopting an instrument at the international level that would be less ambitious, that is, that would not cover all issues that arise in connection with the realization of the surrogacy arrangement. Considering the practical cases to date, the focus of this instrument should be, according to these authors, on the recognition and enforcement of decisions concerning the child's birth record and/or legal parentage decisions (Rokas, 2014: 305). Furthermore, this instrument should create a system of cooperation between Member States, which would take the character of an agreement on international legal assistance (Rokas, 2014: 305).

\section{Work within the Hague Conference on Private International Law}

Work within the Hague Conference on the regulation of issues relating to the status of children, including issues arising from international surrogacy arrangements, began in 2010, when the Special Commission discussed the interconnection of crossborder surrogacy and the 1993 Convention on Intercountry Adoption. ${ }^{4}$

The Special Commission concluded that the number of international surrogacy arrangements was increasing rapidly, and concerns were raised about the uncertainty regarding the status of children born as a result of the surrogacy arrangement. The Special Commission also concluded that the Convention on Intercountry Adoption was inappropriate for the application of cases of international surrogacy

\footnotetext{
${ }^{4}$ Convention of 29 May 1993 on Protection of Children and Co-operation in Respect of Intercountry Adoption. The Convention entered into force on 1 May 1995.
} 
arrangements, and that further research into the legal, and especially private international law issues related to surrogacy, was necessary. ${ }^{5}$

In 2011, the Permanent Bureau was requested to continue gathering information on practical needs in the field of cross-border surrogacy, to offer a comparative legal overview of substantive and private international law rules of different national legislations, and to outline the prospect of reaching a consensus on a global approach. In addition, the Permanent Bureau was tasked with consulting both the legal profession and with healthcare and other relevant experts, whose opinions would be relevant in view of the nature and frequency of problems encountered in this area. ${ }^{6}$ In April 2012, the Council on General Affairs and Policy requested the Permanent Bureau to prepare and distribute questionnaires in order to obtain more detailed information on the scope and nature of the issues of private international law encountered in connection with international surrogacy arrangements, as well as on legal parenting. The questionnaire aimed to explore opinions about needs to be addressed and approaches to be taken. ${ }^{7}$ In 2013 , questionnaires were distributed to practitioners, surrogacy agencies, and health care providers. ${ }^{8}$ During the April 2014 Council meeting, it was concluded that research should continue on the feasibility of developing a multilateral instrument in this area. In this regard, the need to collect information was highlighted, including the receipt of additional answers to questionnaire no. $1{ }^{9}$, especially from countries where international surrogacy arrangements are taking place. ${ }^{10}$ In 2015 , a conclusion was reached on the need to establish an expert group to research the feasibility of developing a multilateral instrument. ${ }^{11}$ The Council on General Affairs and Policy of the Conference in 2016 asked the Expert Group to first consider the rules of private international law concerning the legal status of children in cross-border situations, including those born through international surrogacy arrangements. The Expert's Group found that

\footnotetext{
${ }^{5}$ Para. 25. and 26. Conclusions and Recommendations of the 2010 Special Commission on the practical operation of the 1993 Hague Intercountry Adoption Convention, https://www.hcch.net/en/projects/legislativeprojects/parentage-surrogacy/surrogacy-2010-and-prior, page access 20.12.2019.

${ }^{6}$ Para. $17-20$. Conclusions and Recommendations of the 2011 Council.

${ }^{7}$ Para. 21. Conclusions and Recommendations of the 2012 Council.

${ }^{8}$ See the Conclusions and Recommendations of the 2011 Council (para. 20) and 2012 Council (para. 21).

${ }^{9}$ There were four types of questionnaires developed within the Hague Conference. Those questionnaires were directed to Members of the Hague Conference and other interested states (questionnaire no. 1), to legal practitioners (questionnaire no. 2), health professionals (questionnaire no. 3) and surrogacy agencies (questionnaire 4). https://www.hcch.net/en/projects/legislative-projects/parentage-surrogacy/surrogacy-2011-2015.

10 Para. 3. Conclusions and Recommendations of the 2014 Council.

11 Para. 5. Conclusions and Recommendations of the 2015 Council.
} 
due to both the complexity and the differing approach of States to the problem, no final conclusions could be reached at the meeting on the feasibility of an international instrument in this area, that is, the nature of such an instrument and its scope. ${ }^{12}$ However, one month after the meeting of the Expert Group, the Council called the Expert Group to continue its work in accordance with the mandate provided to it and to emphasize recognition as a mechanism of private international law that could address the challenges of international surrogacy. ${ }^{13}$ Following a meeting in February 2017, the Expert Group agreed on the possibility of developing a binding multilateral instrument that would regulate the recognition of foreign judicial decisions in matters of legal parentage. However, the Expert Group did not take a position on how this instrument is supposed to work. With regard to the establishment and recognition of legal parentage, as well as the application of the rules of private international law on legal parentage to cases of international surrogacy arrangements, given the possible need for additional rules and safeguards in these cases, and due to the different national approaches to this problem, the Expert Group concluded that further consideration and discussion of these issues was needed. ${ }^{14}$ The further work of the Expert's Group emphasized the importance of deepening the debate on the adoption of unique conflict-of-law rules on legal parentage, as well as the correlation of such rules with public documents that record legal parentage. In addition, the Expert's Group highlighted the need for further examination of the possibility of recognizing or accepting foreign public documents in which legal parentage was recorded. Possible provisions for recognition of foreign court decisions were also specified. 15 The 2019 Expert's Group report stresses the importance of ensuring the predictability, security and legal continuity of crossborder legal parentage, taking into account the protection of the human rights of all parties to the proceedings, as well as the best interests of the child. Most experts have acknowledged the possibility of developing a binding multilateral instrument on the recognition of foreign court decisions on legal parentage. Also, agreement was reached on the possibility of developing a special protocol on the recognition of foreign court decisions in cases of international surrogacy arrangements. At this stage, there remain open questions regarding legal parentage when there is no court

\footnotetext{
12 Report of the February 2016 meeting of the Experts' Group on Parentage / Surrogacy".

13 Para. 15. Conclusions and Recommendations of the 2016 Council.

${ }^{14}$ Report of the January / February 2017 meeting of the Experts' Group on Parentage / Surrogacy". See also para. $8-10$. Conclusions and Recommendations of the 2017 Council.

15 Report of the February 2018 meeting of the Experts' Group on Parentage / Surrogacy. See also para. 6 - 7. Conclusions and Recommendations of the 2018 Council.
} 
decision. The Expert's Group report also recommended that the possibility of normative solutions to this issue should be discussed further.

Most Expert's Group members recommended that future work focus not only on the simultaneous development of a general instrument of private international law on the recognition of foreign court decisions in matters of legal parentage (convention) but also on a special protocol on the recognition of foreign court decisions on legal parentage arising from international surrogacy arrangements.

The need for further consideration of other methods that could affect the effectiveness of such instruments was highlighted, such as the conflict-of-law rules for establishing legal parentage or the cross-border recognition of legal parentage status established by operation of law or by acknowledgement. ${ }^{16}$ At the end of 2019, the greatest progress was made in the work of the Expert's Group, when the earlier view was actually confirmed that the issue of legal parentage would be regulated through two legal mechanisms, namely: the convention on the recognition of foreign court decisions in matters of legal parentage, and the special protocol on the recognition of foreign court decisions in legal parentage arising from international surrogacy arrangements. In addition, the Expert Group concluded that additional research was needed in regard to conflict-of-law rules and cooperation rules related to legal parentage. Expert group members emphasized that their work within the Hague Conference on the normative regulation of international surrogacy arrangements is completely neutral, that is, it should not be understood in a way that supports or opposes surrogacy. It has also taken the position that cases of international adoption, including those falling within the scope of the 1993 Convention on Intercountry Adoption, are excluded from the scope of the future convention on the recognition of foreign court decisions in matters of legal parentage. ${ }^{17}$ The aim of the future instrument, in accordance with the recommendations made by the Expert Group in its 2019 report, is to ensure the predictability, certainty and continuity of cross-border legal parentage in all situations for all interested parties, taking into account their rights, and in particular emphasizing the best interests of the child.

\footnotetext{
${ }^{16}$ Report of the January / February 2019 meeting of the Experts' Group on Parentage / Surrogacy.

${ }^{17}$ Report of the October/November 2019 meeting of the Experts' Group on Parentage/Surrogacy.
} 
The Expert's Group has made significant strides when it comes to drafting provisions for a future convention on the recognition of foreign court decisions in cases of legal parentage. The future Convention is intended to refer to the recognition of decisions in matters of legal parentage brought only in contracting states. The Expert's Group also considered the possibility of an optional mechanism for extending the application of the future Convention and for recognizing decisions brought in non-contracting states. With regard to the scope of the future convention, the Expert's Group took the view that this legal mechanism should apply to all decisions on legal parentage, regardless of the name and nature of the decision, and regardless of whether it was brought in the process of establishing or contesting a legal parentage. In addition, the future convention should apply only to the recognition of decisions in matters of legal parentage and not to the rights and obligations arising therefrom (maintenance, inheritance, citizenship). ${ }^{18}$ The Expert's Group agreed that the regime of recognition was carried out by operation of law, with the fulfillment of indirect grounds of jurisdiction in the country in which the decision was taken. ${ }^{19}$ The reasons for refusing recognition of a foreign court decision are defined as well: the institute of public order, taking into account the best interests of the child, violation of the defendant's right to be heard, irreconcilable court decisions or conducting parallel proceedings. ${ }^{20}$

The Expert's Group is of the view that unified conflict-of-law rules would have the capacity to ensure the continuity of cross-border legal parentage in the absence of a foreign court decision on legal parentage (these are situations where legal parentage is established by operation of law or on the basis of an individual act, e.g. acknowledgement of paternity/maternity), and that they should form an integral part of the future convention. ${ }^{21}$ The Expert's Group position regarding the recognition of foreign public documents is interesting. It concluded that it would be useful to include in the future convention a provision on the presumption of validity of legal parentage recorded in a public document issued by a designated competent authority. According to Expert's Group, this provision does not in itself ensure the continuity of legal parentage in cross-border cases, but it can contribute to legal certainty if combined with the conflict-of-law rule. ${ }^{22}$ In this way, the Expert's Group

\footnotetext{
${ }^{18}$ Para. 8. Report of the October/November 2019 meeting of the Experts' Group on Parentage/Surrogacy.

${ }^{19}$ Ibid, para.11.

${ }^{20} \mathrm{Ibid}$, para. 14.

${ }^{21}$ Ibid, para. 15-19.

${ }^{22}$ Ibid, para. 20.
} 
indirectly opted for the conflict of law rules regarding the validity of legal parentage registration in public documents, which could further indicate the application of the law of habitual residence of the surrogate mother or the law of the place where the child is to be born. In addition, the Expert's Group pointed out that it would be useful to define direct rules on international jurisdiction, which would certainly contribute to legal certainty and reduce the risk of irreconcilable judicial decisions. ${ }^{23}$ When it comes to the normative regulation of international surrogacy arrangements, the Expert's Group has opted for the protocol, as a special legal mechanism, the purpose of which is to supplement the future convention. The Expert's Group believe that the provisions of the protocol will ensure the predictability, continuity and certainty of legal parentage arising from international surrogacy arrangements. In terms of scope of application, the protocol will only apply to the recognition of legal parentage established by the realization of international surrogacy arrangements. ${ }^{24}$ Decisions on legal parentage brought after the child was born in the country of origin of the international surrogacy arrangement (or state of the habitual residence of surrogate mother / country of child birth) should be recognized by operation of law in all contracting states, provided that the conditions set out in the protocol are fulfilled. In this connection, the importance of a minimum standard for the protection of the rights and well-being of all parties is particularly emphasized, with special regard to the best interests of the child. ${ }^{25}$ In order to facilitate the recognition of a foreign judgment, the Expert's Group proposes to issue a certificate confirming that the conditions for recognition are fulfilled by the protocol. That certificate should include confirmation that the international surrogacy arrangement is valid in accordance with the law of the state of origin at the time it is concluded and executed. ${ }^{26}$ In this way, it would indirectly introduce a conflict-of-law rule which would mean that with respect to the validity of an international surrogacy arrangement, the law of the state in which the arrangement was concluded, or the law of the habitual residence of surrogate mother, will be applicable. ${ }^{27}$ Since the Expert Group's decision was to regulate the above issues in parallel, through two legal mechanisms, contracting states have the option of acceding to both instruments or only one of them. ${ }^{28}$

\footnotetext{
${ }^{23}$ Ibid, para. 23.

24 Ibid, para. 24.

25 Ibid, para. 30.

${ }^{26}$ Ibid, para. 31.

${ }^{27}$ See. fn. 4. of the Report of the October/November 2019 Meeting of the Experts' Group on Parentage/Surrogacy. 28 The expert group also considered a possibility of introducing a mechanism that would be the link between the two instruments. Ibid, para. 42.
} 


\section{International Regulation of Surrogate Motherhood and the Implications for National Legislation}

The optimal way to regulate cross-border surrogacy would be through a comprehensive instrument of private international law, which would include rules on the international jurisdiction of courts, conflict-of-law rules, rules on the recognition and enforcement of foreign judicial and other decisions, and rules on international cooperation in this field. However, cross-border surrogacy is, by its nature, a complex phenomenon that, in addition to family-law matters, also includes contractual relationships. Such a phenomenon requires appropriate legislative activity (Holocher, 2019: 166-170). Therefore, we believe that the cumulative application of traditional methods of private international law, which would be contained in a single binding instrument, would make it almost impossible to achieve the aims pursued, which are to help ensure predictability, certainty of outcome and legal security in the implementation of international surrogacy arrangements (Blauwhoff \& Frohn, 2016: 236-238). At the international level, no matter what method of regulation of international surrogacy arrangements is given priority ${ }^{29}$, there is consensus on principles that are of paramount importance. These are, namely, the best interests of the child, the legal status of the child and intended parents and the status of the surrogate mother. In view of the above, the intention of the Expert Group was not to include in a comprehensive way a very wide range of relations that are related to the realization of international surrogacy arrangements. Instead, the Expert's Group operating within the Hague Conference has opted for the protocol, as a legal mechanism that, as things stand, will only regulate the recognition of foreign court decisions in matters of legal parentage arising from international surrogacy arrangements. In addition, a general instrument is being adopted - the Convention on the recognition of foreign judgments in matters of legal parentage. In simplified terms, this means that states will be able to choose whether to accept both instruments or just one of them. The protocol is an instrument that supplements the future Convention with respect to matters pertaining to international surrogacy arrangements, that is, which regulates a specific legal relationship, to which the Convention itself does not refer. As already pointed

\footnotetext{
${ }^{29}$ See supra on theoretical attitudes related to pros et cons international regulation by international convention or protocol.
} 
out, the protocol has an optional character as it is not automatically binding on states that would opt for ratification of the Convention. States have the ability to ratify or accede to the protocol separately. Furthermore, most members of the Expert's Group agree that, given the scope, the protocol should cover only the recognition of legal parentage established in cases of international surrogacy arrangements. ${ }^{30}$ Paragraph 2 of the previously described Expert's Group report stated that the protocol only refers to the recognition of foreign court decisions in cases of legal parentage arising from the implementation of international surrogacy arrangement. While there is consensus within the Expert's Group on the inclusion into the protocol of recognition of other methods regarding the way in which legal parentage derived from international surrogacy arrangement is established, it remains uncertain how cases of recognition not established by a court decision will be covered, for example, legal parentage of a child established by operation of law or on the basis of voluntary acknowledgement. Some members of the Expert's Group suggest that this problem could be overcome by issuing a certificate on legal parentage stemming from international surrogacy arrangement. ${ }^{31}$ The certificate should also include confirmation that the international surrogacy arrangement is permitted under the law of habitual residence of surrogate mother at the time it is concluded and executed. By proposing such a provision, the Expert's Group seems to take it for granted to assume that states prohibiting surrogacy arrangements will accept a decision or a certificate confirming that international surrogacy arrangement is permitted under the law of the surrogate mother's country of habitual residence. ${ }^{32}$ Whether or not the Expert's Group proposal to regulate, through a separate protocol, the issue of recognition of foreign court decisions in relation to legal parentage arising from the international surrogacy arrangements, will be ultimately accepted, and whether such an instrument, if adopted, will receive the required number of ratifications depends, among other things, upon the position and interests taken by individual countries with regard to the practice of surrogacy. Namely, in addition to states that explicitly prohibited surrogacy in their national legislations, there are those states where the surrogacy arrangement is considered a lucrative activity, and it is likely that both will be opposed to the conventional arrangement of the international surrogacy (Rokas, 2014: 302). In addition, one of the Expert's Group's proposals is to set minimum standards for eligibility, both on the part of

\footnotetext{
${ }^{30}$ Para. 26. Report of the October/November 2019 Meeting of the Experts' Group on Parentage/Surrogacy.

31 Ibid, para. 41.

${ }^{32}$ F.n. 4. Report of the October/November 2019 Meeting of the Experts' Group on Parentage/Surrogacy.
} 
the surrogate mother and the intended parents. However, practices in states that have a liberal stance when it comes to implementing international surrogacy arrangements have a completely different practice in that they do not control the eligibility of intended parents, so there is a reasonable concern that such a provision could jeopardize the accession of these countries to the future protocol (Rokas, 2014: 303 ). With respect to countries that explicitly prohibit surrogacy, we express doubts about the accession of these countries to a future instrument for the following reason. Namely, for some of these countries to accede to the protocol, there must be a minimum level of acceptance of the surrogacy practice, at least when implemented abroad. In this regard, it is necessary to achieve an equilibrium between the fundamental values of a society expressed through the institute of public policy prohibiting surrogacy, on the one hand (Wells-Greco \& Dawson, 2014: 320-325) and the interests of international surrogacy arrangement participants, that is, their right to private and family life, which is manifested in recognition of legal parentage, on the other. The aforementioned logical reasoning has to take into account the best interests of the child (Thomale, 2017: 468). In support of the view that a significant number of states that have prohibited surrogacy by their national laws will not accede to the protocol on the recognition of foreign judgments arising from international surrogacy arrangements, is an example of the non-adherence of a number of countries to the 1993 Hague Convention on Intercountry Adoption. Namely, Sharia law countries do not recognize and explicitly ban the institute of adoption and they did not accede to the 1993 Hague Convention on Intercountry Adoption. There is a reasonable fear that the same scenario could be replicated in the case of a protocol that should govern international surrogacy arrangements when it comes to countries which explicitly ban surrogacy (Choudhury, 2016). Considering the potential deficiencies of the future protocol in terms of the probable insufficient number of ratifications, as well as the limitations of this instrument, which would only fragmentarily address the many practical problems posed by the implementation of the international surrogacy arrangements, we believe that for the time being, the problem of recognition of legal parentage is better addressed through an existing international instrument on intercountry adoption. The 1993 Convention on Intercountry Adoption, which is based on the principles of international cooperation and the provision of the necessary legal assistance in the implementation of the international adoption procedure, has proved largely successful in protecting the best interests of the child. We believe that an appropriate adaptation of the international adoption procedure to include cases of surrogacy would have the 
capacity to meet the needs of the international surrogacy arrangements, given the necessity of protecting the rights of all participants: the child, intended parents and the surrogate mother. This suggestion in no way encourages new situations of surrogacy, but appropriately addresses those that have already arisen. Such a solution could be acceptable to all states that explicitly prohibit surrogacy through their legislation, since it could also be palatable from the point of view of the criminal law of these states, as surrogacy in these states is mainly considered to be a criminal act (Baillon-Wirtz, 2019: 106-107; Alihodžić, 2017: 26). In a technical, operational sense, the previous solution could be achieved by extending the scope of the Convention on Intercountry Adoption to cases of legal parentage arising from international surrogacy arrangements. An attenuating circumstance in this regard may be the genetic link of the child with at least one intended parent, or the already established legal parentage of one intended parent, whereby the adoption process would then target the other (Thomale, 2017: 471). Thomale points out another possibility. In addition to expediting the adoption procedure in these cases, there is also a possibility of recognizing special status for intended parents or allowing them priority in the list of applicants for child adoption. Following the manner described above, the best interests of the child would be protected, and the attitudes of the ECtHR practice would be satisfied ${ }^{33}$ (Duraković, 2017: 41-55). While interpreting the provision of Article 8 of the European Convention on Human Rights, the court indicated that the child should not be denied the possibility of establishing a parental relationship with his/her genetic parents. Should the Hague Convention on Intercountry Adoption be properly adapted so that the examination of all eligibility requirements provided for adoptive parents would also apply to the intended parents, it could be determined whether it is in the best interests of the child to establish legal parentage with the intended parents in compare to other potential adopters (Thomale, 2017: 472). This would fulfill the requirement emphasized in the court decisions.

\footnotetext{
${ }^{33}$ Mennesson and Labassee, EctHR, No. 65192/11 and 65941, 26 June 2014.
} 


\section{$5 \quad$ Concluding remarks}

Cross-border surrogacy is a complex phenomenon. Having knowledge of the traditional methods of private international law alone is not enough to understand it, nor would their exclusive application in surrogacy cases be sufficient. International surrogacy as a multidisciplinary phenomenon requires a combination of knowledge and understanding of different disciplines in order to achieve a satisfactory solution in the normative field. There are a multitude of factorseconomic, cultural, traditional, medical, social, etc. - that influence the perception of surrogacy, and which play a significant role in determining whether a given country will either allow or prohibit it at the national level. The commitment to adopt an international instrument to regulate cases of international surrogacy arrangements does not yet have a concrete form. At the international level, there is agreement that it is not yet feasible to regulate the international surrogacy with one comprehensive mechanism, which would include all aspects of international surrogacy arrangements (contractual, family law, etc.) in the context of the application of traditional methods of private international law. Instead, the Expert's Group operating within the Hague Conference has opted for a more cautious, minimalist approach, suggesting that at this stage the protocol only covers the recognition of foreign court decisions resulting from the implementation of the international surrogacy arrangements. At present, the fact that there is a huge discrepancy between the national systems of different countries regarding the regulation of surrogacy and the uncertainty regarding the adoption of an international instrument to regulate these issues, we think that for the time being it is better to focus attention on the modification of the 1993 Hague Convention on Intercountry Adoption. We envision that such modifications would encompass issues arising from the implementation of the international surrogacy arrangements and thus provide protection for the child, as the most vulnerable participant of international surrogacy procedure.

Pending the resolution of these complex and intricate issues through adoption and implementation of an international instrument, if the child was born under the procedure of surrogacy arrangement, his or her legal status must be considered, taking into account all the circumstances of the particular case. In other words, this means that public order, as one of the reasons for the (non) recognition of a foreign decision on legal parentage resulting from the implementation of international surrogacy arrangement or a public document confirming legal parentage or 
determining the status of a child, should be interpreted in a way that protects the best interests of the child. Namely, the child is entitled to be informed of his or her biological origin. Furthermore, both the child and his or her legal parents have the right to exercise the right to privacy and family life. These rights stem from and are in accordance with the European Convention on Human Rights, the UN Convention on the Rights of the Child and other international instruments.

\section{References}

Alihodžić, J. (2017) Priznanje pravnog roditeljstva djeteta rođenog putem međunarodnog aranžmana o surogat materinstvu, In: Zbornik radova, Aktuelna pitanja iz oblasti gradanskog prava $u$ Bosni $i$ Hercegovini, Jahorina, pp. 25-40.

Baillon-Wirtz, N. (2019) Surrogate motherhood in France, In: Mostowik, P. Fundamental Legal Problems of Surrogate Motherhood, Global Perspective, (Warszawa: Instytut Wymiaru Sprawiedliwości), pp. 99133.

Blauwhoff, R. \& Frohn, L. (2016) International Commercial Surrogacy Arrangements: the interests of the Child as a Concern of Both Human Rights and Private International Law, In: Paulussen, C. et. al, Fundamental Rights and International and European Law, (Springer), pp. 211-241.

Choudhury, C. A. (2016) Transnational Commercial Surrogacy: Contracts, Conflicts and the Prospects of International Legal Regulation, Florida international University Legal Studies Research Paper Series, No. 16 - 18.

Duraković, A. (2017) Najbolji interes djeteta u praksi Evropskog suda za ljudska prava na primjeru surogat materinstva, In: Zbornik radova „Aktuelna pitanja iz oblasti gradanskog prava u Bosni $i$ Hercegovini, Jahorina, pp. $41-55$.

Holocher, J. (2019) Surrogate motherhood - terminological considerations. Three perspectives: theory and philosophy of law, legal doctrine, and public debate, In: Mostowik, P. Fundamental Legal Problems of Surrogate Motherhood, Global Perspective, (Warszawa: Instytut Wymiaru Sprawiedliwości), pp. 163 - 171.

Margalit, Y. (2016) From Baby M to Baby M(anji): Regulating International Surrogacy Agreements, Brooklyn Journal of Law and Policy, 24(1), pp. 68-81.

Meilhac-Perri, M. (2014) National Regulation and Cross-Border Surrogacy in France, Yearbook of Private International Law, 16, pp. $284-286$.

Muminović, E. (2006) Procesno međunarodno privatno pravo (Pravni fakultet Univerziteta u Sarajevu), pp. 83-84.

Pluym, L. (2014) Policy Considerations Concerning a Family Law Statute for Surrogate Motherhood in Belgium, In: J. De Bruyne, M. de Potter de ten Broeck, I. Vom Hiel, Policy within and through law: Proceedings of the 2014 ACCA-Conference, pp. 337-338.

Rokas, K. (2014) National Regulation and Cross-Border Surrogacy in European Union Countries and Possible Solutions for Problematic Situations, Yearbook of Private International Law, 16, pp. 300 $-306$.

Thomale, C. (2017) State of play of cross-border surrogacy arrangements - is there a case for regulatory intervention by the EU? Journal of Private International Law, 13(2), pp. 471-473.

Trimmings, K., Beaumont, P. (2011) International Surrogacy Arrangements: an Urgent Need for Legal Regulation at the International Level, Journal of Private International Law, 7(3), pp. 633-647.

Wells, M. \& Dawson, H. (2014) Inter-country Surrogacy and Public Policy: Lessons from the European Court of Human Rights, Yearbook of Private International Law, 16, pp. 315-343. 